\title{
The Effect of Iron Impurities on Transition Metal Catalysts for the Oxygen Evolution Reaction in Alkaline Environment: Activity Mediators or Active Sites?
}

\author{
Ioannis Spanos $^{1}$ (D) Justus Masa ${ }^{1}$ (D) Aleksandar Zeradjanin ${ }^{1}$ (D) $\cdot$ Robert Schlögl $^{1,2}$ (D)
}

Received: 19 October 2020 / Accepted: 24 November 2020 / Published online: 18 December 2020

(c) The Author(s) 2020

\begin{abstract}
There is an ongoing debate on elucidating the actual role of Fe impurities in alkaline water electrolysis, acting either as reactivity mediators or as co-catalysts through synergistic interaction with the main catalyst material. This perspective summarizes the most prominent oxygen evolution reaction (OER) mechanisms mostly for Ni-based oxides as model transition metal catalysts and highlights the effect of Fe incorporation on the catalyst surface in the form of impurities originating from the electrolyte or co-precipitated in the catalyst lattice, in modulating the OER reaction kinetics, mechanism and stability.
\end{abstract}

\section{Graphic Abstract}

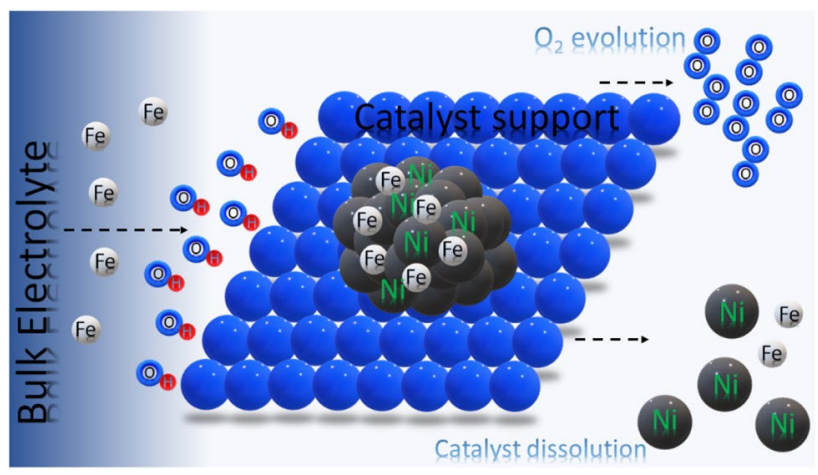

Keywords Alkaline water electrolysis $\cdot$ Electrocatalysis $\cdot$ Fe impurities $\cdot$ Reaction mechanism

\section{Introduction}

We live in an era where chemical energy conversion via electrocatalytic processes has gained a considerable interest due to the huge negative impact of fossil fuels on the

Ioannis Spanos

ioannis.spanos@cec.mpg.de

1 Department of Heterogeneous Reactions, Max Planck Institute for Chemical Energy Conversion, Stiftstr. 34-36, 45470 Mülheim an der Ruhr, Germany

2 Department of Inorganic Chemistry, Fritz Haber Institut der Max-Planck-Gesselschaft, Faradayweg 4-6, 14195 Berlin, Germany environment. The direct electrochemical conversion of chemical bonds of reactants/precursors into usable fuels like hydrogen, methanol, ethanol and other carbonaceous fuels, by harvesting natural energy sources like wind and most importantly solar and the storage of excess energy into batteries and supercapacitors has opened new and exciting pathways during the last few decades in the field of energy economy. All this effort arises from the realization that if nature can so elegantly photosynthesize fuels, why not use similar principles to imitate nature. Thus, a realistic candidate for storing solar energy in the form of chemical bonds and their subsequent harvesting, would be hydrogen. 
Water electrolysis, is consequently frequently considered as a clean and scalable technology for harvesting hydrogen via small or large scale electrolyzers, which are all part of the modern 'hydrogen economy' infrastructure. However, even though water electrolysis has been studied for over 200 years, the complexity of all the processes taking place at the 3-phase solid/liquid/gas boundaries on the anode and the cathode still hides many challenges, especially for the anode part where the very energy demanding oxygen evolution reaction (OER) takes place. Amongst the most challenging issues, is the necessity for advanced materials of high activity and most prominently stability for both acidic and alkaline conditions. This is where Pourbaix diagrams play a crucial role by supplying thermodynamic information on how certain catalysts might behave upon $\mathrm{pH}$ and potential changes.

As such, for acidic conditions Ir- and Ru-based oxides and their respective alloys are primarily used, while in alkaline conditions one can find the more traditional Ni-based oxides like Raney-Nickel already dating back to the 1930s and a variety of alloys like $\mathrm{Ni} / \mathrm{Co}, \mathrm{Ni} / \mathrm{Mn}, \mathrm{Ni} / \mathrm{Mo}, \mathrm{Ni} / \mathrm{Zn}$ and $\mathrm{Ni} / \mathrm{Fe}$, with the latter having the highest activity. In this perspective we will give an overview of how in particular Fe incorporation in the catalyst lattice or catalyst surface changes the structural properties, surface conductivity, catalytic activity and stability of Ni-based OER catalysts. Relevant to all this is the effect of Fe impurities inherently present in $\mathrm{KOH}$, which is the electrolyte of choice for alkaline electrolyzers. Even extremely low $\mathrm{Fe}$ amounts in the order of $\mu \mathrm{g} / \mathrm{L}$ in the electrolyte is enough to have a dramatic impact on catalyst performance, thus making it imperative to understand this very important unusual phenomena as well as suggests that is necessary to clarify how electrolyte additions can enhance reaction kinetics.

\section{General Aspects of Water Oxidation}

To acquire hydrogen by electrolysis, i.e. the electrocatalytic splitting of water into its constituents, hydrogen and oxygen, energy is required, which will provide the necessary electrons to drive the 2 half-reactions involved in the overall water splitting reaction:

$2 \mathrm{H}_{2} \mathrm{O}_{(\mathrm{l})} \rightarrow 2 \mathrm{H}_{2(\mathrm{~g})}+\mathrm{O}_{2(\mathrm{~g})}($ overall reaction)

\subsection{Reaction Mechanism of OER in Alkaline Media}

Oxygen evolution reaction (OER) is a 4-electron process which takes place at the anode, in an electrolysis cell (2, 3 ). Compared to HER, the OER process has more sluggish kinetics, where $\mathrm{M}$ represents surface active sites of the catalysts and $\mathrm{M}-\mathrm{OOH}, \mathrm{M}-\mathrm{O}$ and $\mathrm{M}-\mathrm{OH}$ are the adsorption intermediates of each reaction step. Generally, the mechanism of OER is believed to proceed in initial step by $\mathrm{H}_{2} \mathrm{O}$ deprotonation in acidic electrolytes or $\mathrm{OH}^{-}$electroadsorption in alkaline electrolytes, both resulting in $\mathrm{M}-\mathrm{OH}$ formation, followed by the other three steps including oxidizing $\mathrm{M}-\mathrm{OH}$ into $\mathrm{M}-\mathrm{O}, \mathrm{M}-\mathrm{O}$ into $\mathrm{M}-\mathrm{OOH}$ and finally $\mathrm{M}-\mathrm{OOH}$ into $\mathrm{O}_{2}(4-8)$.

Cathode reaction:

$2 \mathrm{H}_{2} \mathrm{O}_{(\mathrm{l})}+2 \mathrm{e}^{-} \rightarrow \mathrm{H}_{2}+2 \mathrm{OH}^{-} \quad \mathrm{E}_{c}^{0}=-0.83 \mathrm{~V}$

Anode reaction:

$2 \mathrm{OH}^{-} \rightarrow \mathrm{O}_{2}+\mathrm{H}_{2} \mathrm{O}_{(\mathrm{l})}+2 \mathrm{e}-E_{a}^{0}=+0.40 \mathrm{~V}$

Proposed OER mechanism under alkaline conditions

$\mathrm{M}+\mathrm{OH}^{-} \rightarrow \mathrm{M}-\mathrm{OH}+\mathrm{e}^{-}$

$\mathrm{M}-\mathrm{OH}+\mathrm{OH}^{-} \rightarrow \mathrm{M}-\mathrm{O}+\mathrm{H}_{2} \mathrm{O}_{(1)}+\mathrm{e}^{-}$

$2 \mathrm{M}-\mathrm{O} \rightarrow 2 \mathrm{M}+\mathrm{O}_{2(\mathrm{~g})}$

$\mathrm{M}-\mathrm{O}+\mathrm{OH}^{-} \rightarrow \mathrm{M}-\mathrm{OOH}+\mathrm{e}^{-}$

$\mathrm{M}-\mathrm{OOH}+\mathrm{OH}^{-} \rightarrow \mathrm{M}+\mathrm{O}_{2(\mathrm{~g})}+\mathrm{H}_{2} \mathrm{O}_{(\mathrm{l})}+\mathrm{e}^{-}$

Alternatively, a more sluggish 2-electron pathway involving peroxide formation $[1,2]$.

\subsection{Basic Thermodynamics}

Water electrolysis, is an endergonic reaction that requires a theoretical amount of $\Delta \mathrm{G}^{0}=+237 \mathrm{~kJ} \mathrm{~mol}^{-1}$ of electrical energy (Gibbs free energy of the reaction) to be applied at standard conditions for $1 \mathrm{~mol}$ of water to split into hydrogen and oxygen. At the same conditions, the molar enthalpy change of the reaction $\Delta \mathrm{H}^{0}$, which is the heat formation of one mole of water, is $286 \mathrm{~kJ} \mathrm{~mol}^{-1}$. Using Eq. (9) and substituting the number of electrons participating in the reaction with 2 and the Faraday's constant with $96,485 \mathrm{C} / \mathrm{mol}$ the reversible electrolysis cell voltage of $1.229 \mathrm{~V}$ at standard conditions (STP) can be calculated, which is the minimum potential required to split water. However, Eq. (10) gives the total energy requirement for the reaction to proceed, both the free energy term $\left(\Delta \mathrm{G}^{0}\right)$ and entropic $\left(\mathrm{T} \Delta \mathrm{S}^{0}\right)$, with the latter term having a value of $49 \mathrm{~kJ} \mathrm{~mol}^{-1}$.

$\Delta \mathrm{G}^{0}=\mathrm{nFE}^{0}$

$\Delta \mathrm{H}^{0}=\Delta \mathrm{G}^{0}+\mathrm{T} \Delta \mathrm{S}^{0}$ 
Thus, the total energy requirement is $286 \mathrm{~kJ} \mathrm{~mol}^{-1}$, which translates into a potential of $1.481 \mathrm{~V}$, called the thermoneutral potential of the reaction, which is the potential above which the reaction proceeds as exothermic, while in the potential range 1.229-1.481 V (between reversible and thermoneutral voltage) the reaction proceeds as endothermic [3]. In reality however, electrolyzers emit heat due to operation voltages between 1.8 and $2.2 \mathrm{~V}$, not only to acquire higher hydrogen yields but also to overcome losses related to the reaction (sluggish kinetics, poor mass transport of reactants and products) and ohmic resistances of the cell connections and ions in solution, also called activation, concentration and resistance overpotentials respectively.

\subsection{Catalyst Evaluation}

In order to evaluate catalyst performance for the OER certain electrochemical and spectroscopic techniques are used to acquire information on the activity, stability and faradaic efficiency. It is well established that, linear sweep voltammetry (LSV) and/or cyclic voltammetry (CV) are utilized for kinetic analysis, including diagnostics of redox chemistry. Also, Faradaic efficiency is typically evaluated by comparing total mass of products using Faraday's law with the measured mass of produced gas. However, only recently experimental setups are built that can quantify stability via in-situ measured dissolution rate.

\subsubsection{Catalyst Dissolution}

Measuring the amount of dissolved catalyst during OER is a very important metric for catalyst evaluation. Therefore, there are two different pathways to measure catalyst dissolution either ex-situ (post mortem) or in-situ analysis of the dissolution products in the electrolyte used. In the latter case, importantly transient analysis of dissolution rates can be performed by combining traditional electrochemistry with Induced Coupled Plasma (ICP) spectrometry, which has proved to be a very powerful tool for the determination of catalyst deterioration [4], or by other techniques, like electrochemical Quartz Crystal Microbalance (eQCM) which can also detect extremely low catalyst mass changes in the order of $\mathrm{ng} \mathrm{s}^{-1}$.

All this information described above can be converted into performance metrics and be depicted into a single chart called spider graph which allows the simultaneous comparison of different catalysts under identical conditions. These metrics can be diverse depending on the experimental techniques that are used and can be used to categorize catalysts according to their stability and activity. To do so, we have chosen 6 different metrics (with $\mathrm{E}_{\mathrm{J}=10 \mathrm{~mA} \mathrm{~cm}}{ }^{-2}$ geo and $E_{O E R, \text { onset }}$ influencing activity while $\Delta \mathrm{J}_{\mathrm{LSV}} \%, n_{C P, 2 h} \%$, $n_{\text {Faradaic }}$ and $\Delta \operatorname{cor}_{C P, 2 h}$ influencing stability) and 5 different hypothetical model catalysts (Fig. 1a-e), each one favoring activity, stability or both (Fig. 1e: ideal case). The values of each marker for these model catalysts were chosen carefully to represent each category of catalysts [4].

\section{Sate of the Art Catalysts}

Already starting from late 60s and early 70s [5], there have been substantial interest in water electrolysis and a wide variety of catalyst classes have been investigated over the years.

\subsection{Precious Metal Oxides}

Noble metal-based catalysts are known to be some of the most active catalysts for both alkaline and acidic water electrolysis [6] already since the 60s, with Damjanovic et al being one of the first to study OER kinetics on Pt, Ir and Rh-based catalysts [7]. Since then many studies have dealt with the effect of crystal structure [8-10], alloying and/or doping [11] of Ir and Ru which are the most promising OER catalysts in acidic conditions, with the purpose of identifying those conditions that can merge together two different properties of these materials, that is, the superior catalytic activity of Ru-based oxides with the superior stability of Irbased oxides. Both those metal oxides have a rutile crystal structure, where $\mathrm{Ru}$ and $\mathrm{Ir}$ are located in the center of an octahedral site with oxygen in the corners, with each octahedron connecting to each other through sharing the corners. $\mathrm{IrO}_{2}$ is known to have far better catalytic activity in the amorphous state compared to its crystalline counterparts, although rutile- $\mathrm{IrO}_{2}$ shows considerably better stability. Comparatively, $\mathrm{RuO}_{2}$ although the most active OER catalyst known today, seriously lacks stability, since as Cherevko et al. [12] have demonstrated, $\mathrm{RuO}_{2}$ is unstable and heavily dissolved during OER under high anodic polarization conditions, compared to $\mathrm{IrO}_{2}$. According to the proposed mechanism for the observed catalyst dissolution, $\mathrm{RuO}_{2}$ at high anodic polarization acquires the $\mathrm{Ru}^{4+}$ oxidation state $\left(\mathrm{Ru}^{4+}\right) \mathrm{O}_{2}$ and subsequently transforms into the hydrous compound $\mathrm{RuO}_{2}(\mathrm{OH})_{2}$ which under deprotonation leads to the formation of a high oxidation state $\left(\mathrm{Ru}^{8+}\right) \mathrm{O}_{4}[13-15]$ which is readily soluble in the solution.

\subsection{Transition Metal Oxides and hydroxides}

$\mathrm{Ni}$ - and Co-based materials have been used for many decades as OER catalysts due to their superior catalytic activity and stability in alkaline conditions, their environmental friendliness, low cost and material abundance. From a synthesis point of view both types of catalysts can be realized in nanosized powders which is crucial for 
(a)

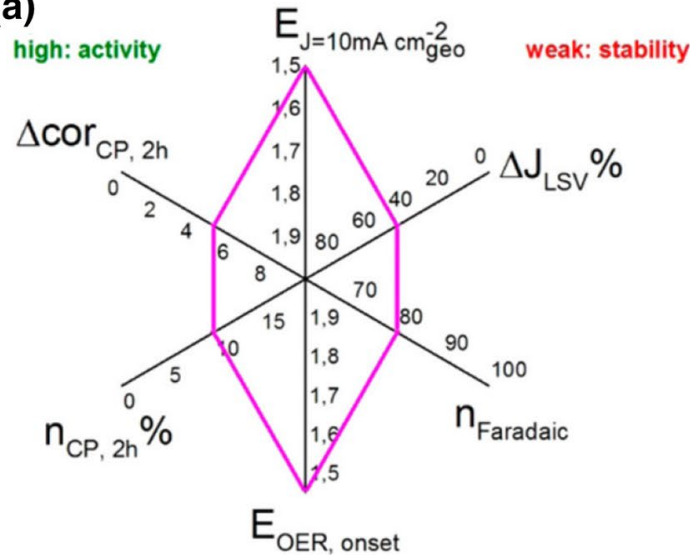

(c)

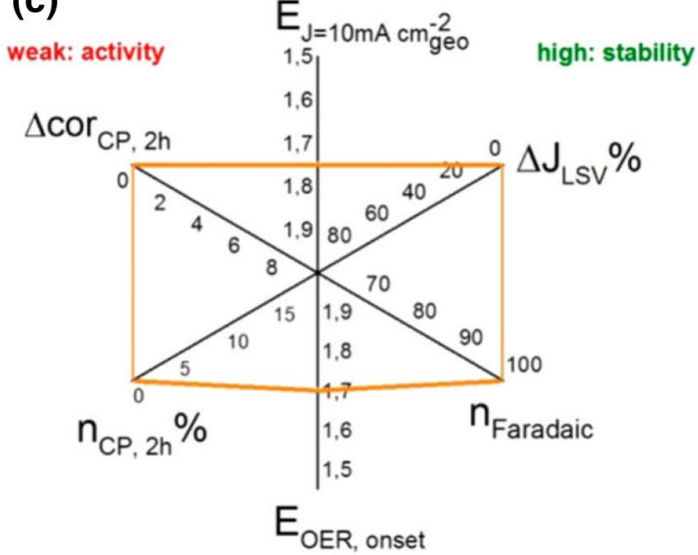

(b)

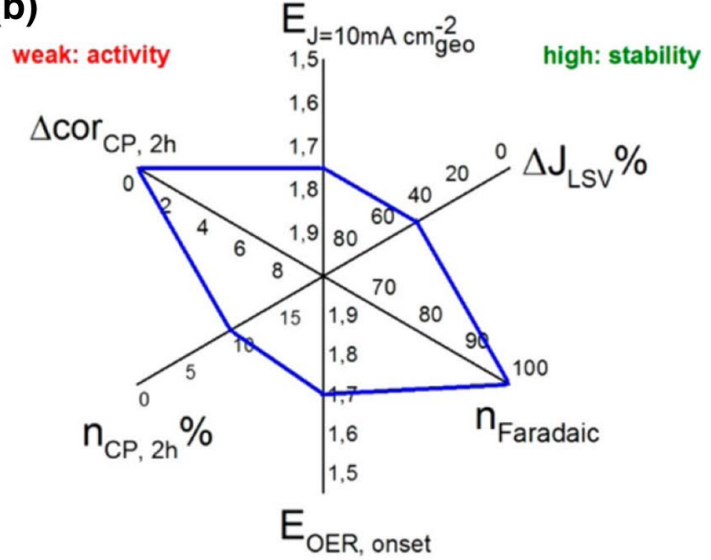

(d)

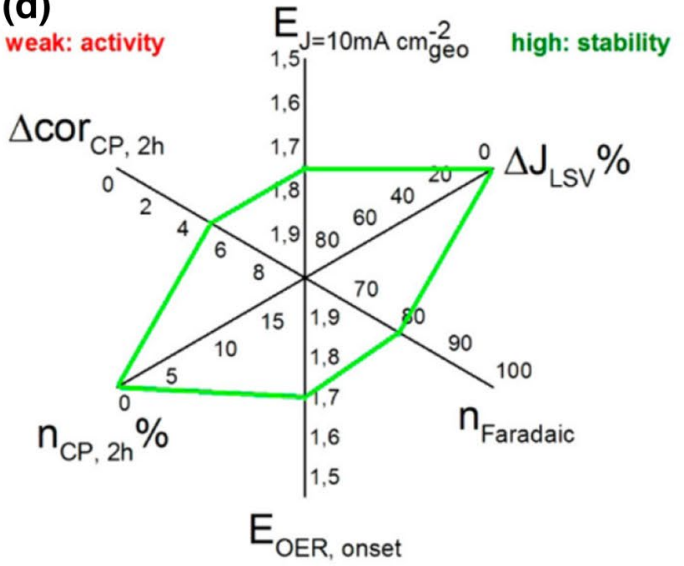

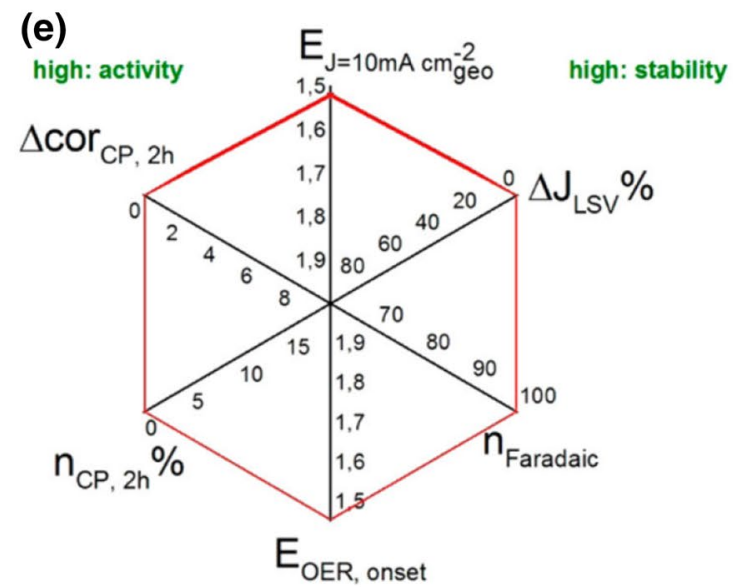

Fig. 1 Spider plots of different catalyst performance metrics for efficient catalyst comparison under similar conditions. Reprinted (adapted) with permission from [4]. Copyright (2020) American Chemical Society

high electrocatalytic surface area and improved reaction efficiency. The structures of such catalysts are typically, spinel, perovskites and layered double hydroxides, where the OER overpotential at $10 \mathrm{~mA} / \mathrm{cm}^{2}$ is typically in the range of 200-400 $\mathrm{mV}$ depending on the type of catalyst and the catalyst support.
Perovskites have the general formula $\mathrm{ABX}_{3}$ and $\mathrm{ABO}_{3}$ for the equivalent oxides, where $\mathrm{A}$ is alkaline- and/or rare-earth metal of larger size than B which is a transition metal and is centered in an octahedron of oxygen atoms surrounding it, thus completing the structure of the perovskite. The conductivity of a perovskite is mostly due to an overlap in the 
d-orbital of the transition cation B and the p-orbital of the oxygen anions and the available d-electrons [16], which Matsumoto et al. connected in a study on a $\mathrm{La}_{1-\mathrm{x}} \mathrm{Sr}_{\mathrm{x}} \mathrm{Fe}_{1-\mathrm{y}} \mathrm{Co}_{\mathrm{y}} \mathrm{O}_{3}$ system for the OER, to the activity of the catalyst, due to the d-band distribution and the higher oxidation state of the Co ion. The mixed oxidation state of $3^{+}$and $4^{+}$of some perovskites depend on the oxidation state of cation A and has been linked [2] to their high catalytic activity for the OER.

Spinel-type oxides have a more complex structure than perovskites with two cation sites surrounded by oxygen atoms in an octahedral and tetrahedral orientation. Typical catalysts from this group of materials are $\mathrm{Co}_{3} \mathrm{O}_{4}, \mathrm{Fe}_{3} \mathrm{O}_{4}$, Nidoped $\mathrm{Co}_{3} \mathrm{O}_{4}$ or $\mathrm{NiCo}_{2} \mathrm{O}_{4}$ and many more. These materials typically have high conductivities due to high carrier mobilities, like Li-doped $\mathrm{Co}_{3} \mathrm{O}_{4}$ and $\mathrm{NiCo}_{2} \mathrm{O}_{4}$ which both have higher conductivities and activities compared to $\mathrm{Co}_{3} \mathrm{O}_{4}$. Doping of such catalysts with various metals can readily alter the structural and electrocatalytic properties of these materials. What was universal, independently from lattice type, was that impurities affected catalytic performance drastically.

\section{Effect of Impurities on Electrocatalysis}

The susceptibility of electrocatalytic reactions to the presence of even the slightest amount of impurity traces in the reaction medium, electrochemical vessels [17] or at the catalyst itself has been known for many decades. Their sizable effect on the reaction mechanism, selectivity, catalyst stability and activity, by masking/blocking or otherwise altering the active sites for the relevant reaction is well documented.

Kwon et al. showed by using a combination of online HPLC and in situ FTIR that the addition of bismuth on a carbon supported platinum electrode (catalyst denoted as $\mathrm{Pt}-\mathrm{Bi}$ ) is capable of oxidizing glycerol to dihydroxyacetone with $100 \%$ selectivity, by blocking the primary alcohol oxidation pathway [18].

Pumera et al. showed that trace amounts of Fe within remnant metallic nanoparticle impurities of Co and Mo nanoparticles in MWCNT are able to catalyze peroxide reduction [19], while Ullman et al. [20] reported the effect of $\mathrm{Co}(\mathrm{II})$ on the apparent water splitting activity of $\mathrm{Co}(\mathrm{III})_{4} \mathrm{O}_{4}$ molecular cubanes, which is only triggered by the formation of the well-known Co-OEC (oxygen evolving complex) cobaltate catalyst during synthesis [21]. Bockris investigated the effect of trace amounts of Pt on the ORR and OER activity of a $\mathrm{Na}_{\mathrm{x}} \mathrm{WO}_{3}$ crystal, which increased up to 4 orders of magnitude as Pt was introduced and it approached the activity of pure $\mathrm{Pt}$ at $400 \mathrm{ppm}$ of $\mathrm{Pt}$ in the crystal. The specific activity on a bronze crystal was $10^{3}$ times that of bulk Pt due to a spillover effect of adsorbed intermediates from Pt on the bronze giving rise to the enhanced catalytic activity [22].
Likewise, during the oxygen reduction reaction (ORR) on Pt catalyst surfaces, the $\mathrm{Pt}$ sites can be readily covered by various anions, like $\mathrm{CN}^{-}, \mathrm{F}^{-}, \mathrm{Cl}^{-}, \mathrm{Br}^{-}$and $\mathrm{I}^{-}$[23-26] present in the electrolyte or in the catalyst synthesis medium, with $\mathrm{Cl}^{-}$anions being commonly known for their presence in reference electrodes like the calomel $\left(\mathrm{Hg} / \mathrm{Hg}_{2} \mathrm{Cl}_{2}\right)$ and $\mathrm{Ag} / \mathrm{AgCl}$ and are capable of blocking Pt active sites thus hindering the reaction. These anions can be released in the electrolyte due to a concentration gradient near the reference electrode surface which can enhance the escape of such anions from the electrode compartment into the electrolyte in the course of prolonged use. In the case of $\mathrm{CN}^{-}$anions, those can have a positive effect on the ORR activity of $\mathrm{Pt}$ in $\mathrm{H}_{2} \mathrm{SO}_{4}$ and $\mathrm{H}_{3} \mathrm{PO}_{4}$ by blocking the strongly adsorbing sulfates and phosphates anions from the electrolyte which otherwise inhibit ORR activity.

Inadvertently doping $\mathrm{sp}^{2}$ carbon nanomaterials like the well-known 'metal-free' graphite-based ORR catalysts, with $\mathrm{Fe}, \mathrm{Co}, \mathrm{Ni}, \mathrm{Mn}, \mathrm{Mo}, \mathrm{V}$ and $\mathrm{Cr}$ impurities coming from the synthesis medium, can have a great impact on their activity as well [27-36]. Masa et al. showed that trace Fe metal impurities in supposedly metal-free nitrogen doped carbon-based catalysts for the ORR, were mostly responsible for their remarkable activity [37]. In related studies, a manganese oxide catalyst supported on graphene derived from graphite containing trace iron impurities was shown to exhibit superior ORR and OER activity compared to a similar catalyst supported on Fe impurity-free graphene [38]. Meanwhile, when entrapped inside carbon nanotubes (CNTs), residues of transition metals used as catalysts for CVD growth of the CNTs have been demonstrated to markedly influence the electrocatalytic properties of the CNTs $[39,40]$.

Finally, Corrigan [41] was the first to investigate the promotional effect of $\mathrm{Fe}$ impurities from as low as $0.01 \mathrm{wt} \%$ up to a $1: 1 \mathrm{Ni}$ :Fe ratio on the (OER) activity of Ni-oxide films (Fig. 2) and suggested his work as a future reference for catalyst design, although neglected up until early 2010s'.

\subsection{Effect of Fe on Transition Metal OER Electrocatalysts}

Typically alloying of $\mathrm{Ni}$ - and Co-based oxides readily increases their activity due to surface area, conductivity enhancement, and electronic structure related phenomena affecting the $\mathrm{OH}^{-}$adsorption bond strength on the catalyst surface. Bockris et al. [42] and Trassati [43] explained the high performance of $\mathrm{Ni}$ oxides in terms of surface Lewis acidity and changing of the $\mathrm{M}-\mathrm{OH}$ bond strength (Sabatier principle) with the addition of a second cation in the oxide's lattice, while Li et al. [44], hypothesized that an enhanced $\mathrm{Ni}-\mathrm{O}$ covalency and thus greater oxyl character, due to the presence $\mathrm{Fe}^{3+}$ results in a more active catalyst. 


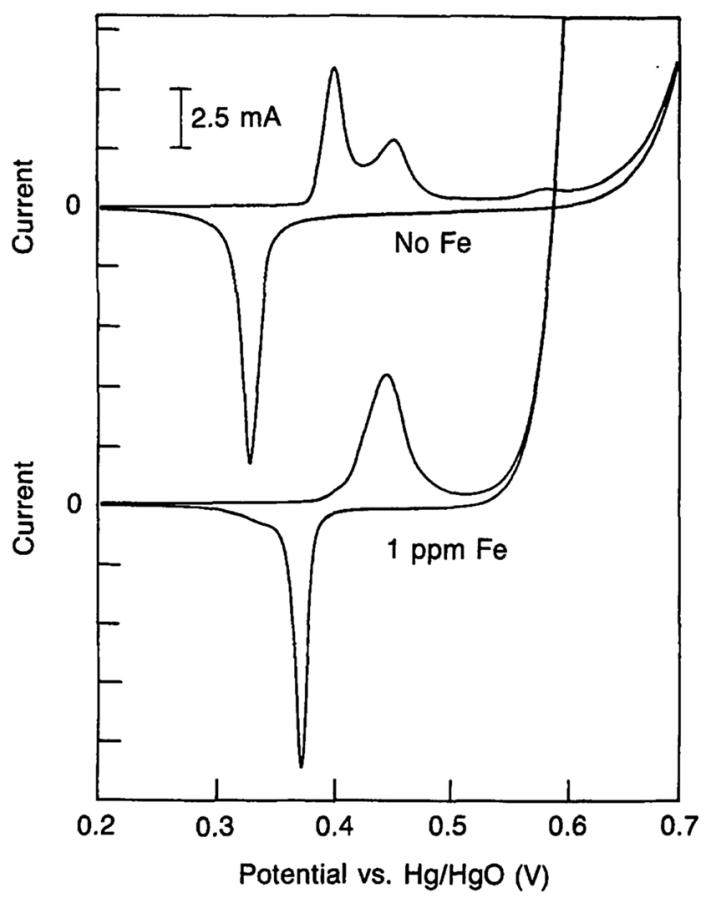

Fig. 2 Effect of 1 ppm Fe impurities in $25 \mathrm{wt} \% \mathrm{KOH}$ on a Nickel oxide thin film catalyst. Reprinted (adapted) with permission from [41]. Copyright (2020) IOP Publishing

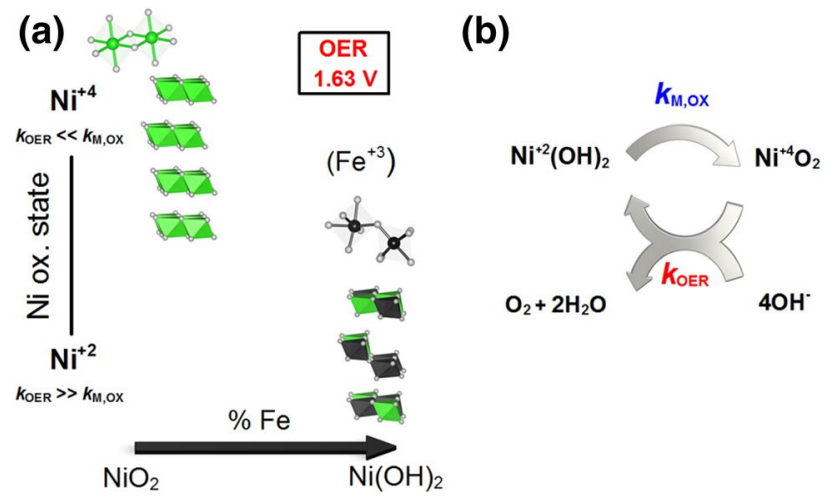

Fig. 3 a XAS-derived structural motifs prevalent during OER catalysis at high and intermediate $\mathrm{Ni}$-content. At high Ni-content the dominating host is the layered $\gamma-\mathrm{NiOOH}$ (a "NiO ${ }_{2}$ " phase) with octahedrally coordinated edge-sharing $\mathrm{Ni}^{4+}$. In the presence of $\mathrm{Fe}$ there is a mixture of edge- and corner sharing octahedra.76,90,91 Above $4 \%$ $\mathrm{Fe}$, the dominant host is the $\mathrm{Ni}(\mathrm{OH})_{2}$ with $\mathrm{Ni}^{2+}$. b Simplified scheme of the electrochemical water splitting cycle with metal oxidation rate constant, $\mathrm{k}_{\mathrm{M}, \mathrm{OX}}$, and the catalytic OER rate constant, $\mathrm{k}_{\mathrm{OER}}$. Reprinted (adapted) with permission from [45]. Copyright (2020) American Chemical Society

Two different studies by Görlin et al. [45] (Fig. 3) and Bell et al. [46] report a change in the local environment of $\mathrm{Ni}$ in the $\mathrm{Ni}-\mathrm{Fe}$ catalysts upon $\mathrm{Fe}$ addition, which affects not only the oxidation state of $\mathrm{Ni}$ but also its activity.
On the other hand Friebel [47] reported a change in the $\mathrm{Fe}-\mathrm{O}$ bond length in a $\mathrm{NiFeO}_{\mathrm{x}} \mathrm{H}_{\mathrm{y}}$ catalyst compared to the same bond length in $\mathrm{FeO}_{\mathrm{x}} \mathrm{H}_{\mathrm{y}}$ catalyst, also reporting a lower overpotential for the $\mathrm{Fe}-\mathrm{O}$ sites compared to the $\mathrm{Ni}-\mathrm{O}$ ones (Fig. 4). Although both authors see no change in the oxidation state of $\mathrm{Fe}\left(\mathrm{Fe}^{3+}\right)$, Bard [48] reported an $\mathrm{Fe}^{3+}$ to $\mathrm{Fe}^{4+}$ change using a surface-interrogation scanning electrochemical microscope. As a result, whether the addition of $\mathrm{Fe}$ alters the bond length of $\mathrm{Fe}-\mathrm{O}, \mathrm{Ni}-\mathrm{O}$ or $\mathrm{Ni}-\mathrm{O}-\mathrm{Fe}$ remains still unclear.

\subsection{Transition Metal Layered-Type Double Hydroxide (LDH) Catalysts}

The main attribute of this type of catalysts is their high surface area due to their mesoporous hierarchical 3D structure, thus they are the most promising type of catalyst materials for alkaline water electrolysis. The structure of LDHs (in the forms of metal hydroxides and oxyhydroxides) comprises of stacked layers with protons $\left(\mathrm{H}^{+}\right)$and water molecules and alkali cations $\left(\mathrm{Na}^{+}\right.$and $\left.\mathrm{K}^{+}\right)$intercalated in between the layers and the transition metals forming an octahedron with oxygen anions on each corner of the octahedron, which further interconnect with each other through edge sharing, thus forming 2D structures, with $\mathrm{Ni}$ and Co typically present in the center of the octahedrons. Depending on the distance between the layers, $\beta$ - or $\gamma$-type $\mathrm{NiOOH}$ is formed, with the $\beta$-type being the most active for OER electrocatalysis.

Their activity is based on the $\mathrm{Ni}^{3+}$ or mixed valence $\mathrm{Ni}^{3+}$ and $\mathrm{Ni}^{4+}$ nature of the $\mathrm{NiOOH}$ structure. There are four nickel oxide phases before OER starts [49] and transformation of the $\mathrm{Ni}(\mathrm{OH})_{2}$ phase to the $\mathrm{NiOOH}$ phase via the transition (11) has been known to be the principle mechanism of catalyst activation before OER starts [50,51], as shown in the Bode diagram in Fig. 5.

$\mathrm{Ni}(\mathrm{OH})_{2}+\mathrm{OH}^{-} \rightarrow \mathrm{NiOOH}+\mathrm{H}_{2} \mathrm{O}+\mathrm{e}^{-}$

The main mechanism for $\mathrm{Ni}$ - based catalyst activation during OER can be divided into a few steps: (1) spontaneous formation of a hydrous $\alpha-\mathrm{Ni}(\mathrm{OH})_{2}$ upon immersion in alkaline electrolyte (2) ageing of the hydroxide layer to a $\beta$ - $\mathrm{Ni}(\mathrm{OH})_{2}$, (3) transformation of the $\alpha$ - and $\beta$-hydroxides respectively to $\gamma-\mathrm{NiOOH}$ and $\beta-\mathrm{NiOOH}$ below $450 \mathrm{mV}$ versus $\mathrm{Hg} / \mathrm{HgO}$ (4) and finally $\beta-\mathrm{NiOOH}$ can be further oxidized to $\gamma-\mathrm{NiOOH}$ when the potential is higher than $600 \mathrm{mV}$ versus $\mathrm{Hg} / \mathrm{HgO}$ [46, 52-59].

However, Yeo et al. [59] used in situ Raman spectroscopy to identify the composition of the active phase on the surface of nickel electrodes and concluded that a different phase other than $\gamma-\mathrm{NiOOH}$ was formed upon further oxidation of $\beta-\mathrm{NiOOH}$, which was responsible for the high activity of 


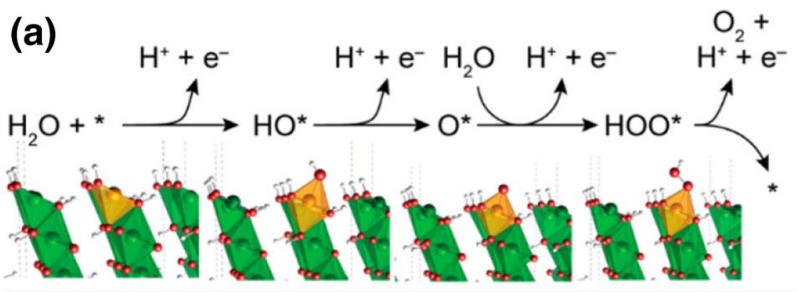

(b)

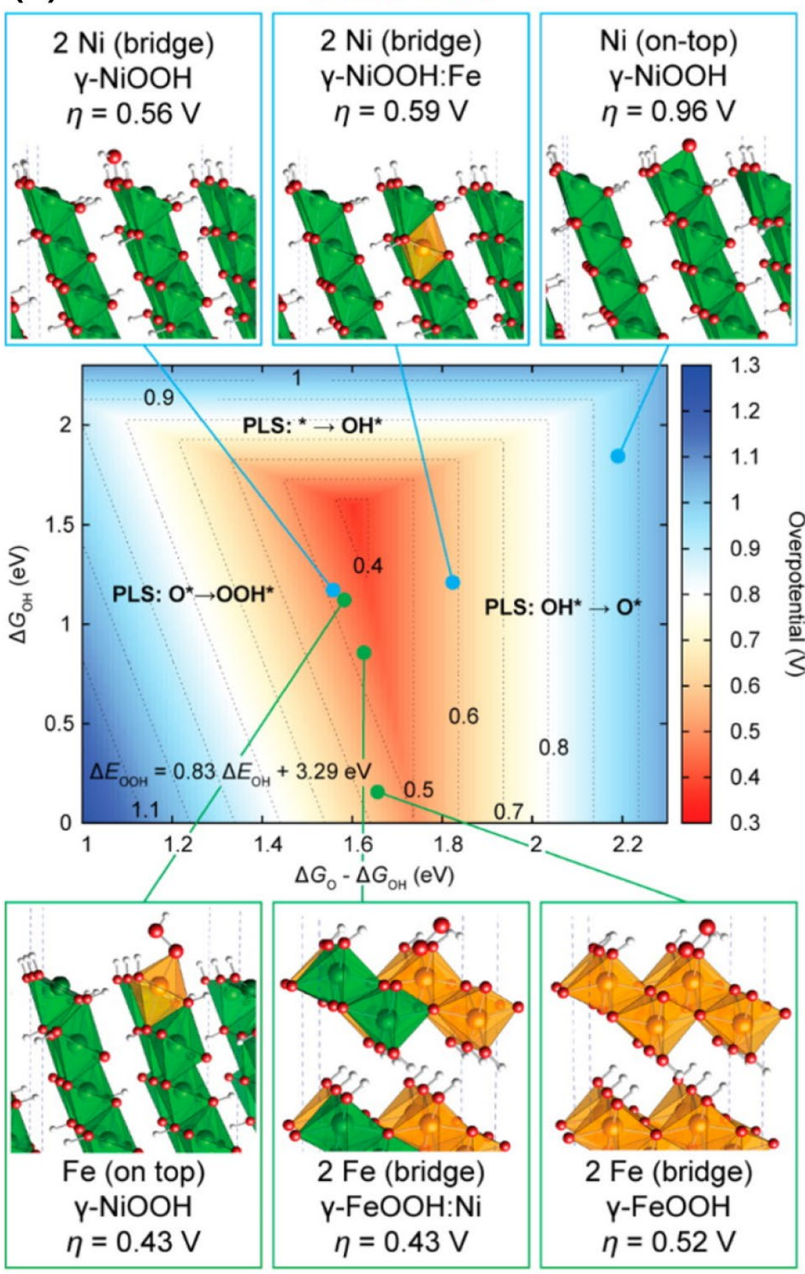

OER at Fe site

Fig. 4 Theoretical OER overpotentials at Ni and Fe surface sites for impure and doped $\gamma-\mathrm{NiOOH}$ and $\gamma-\mathrm{FeOOH}$ model structures. a Proposed OER pathway with intermediates $\mathrm{HO}^{*}, \mathrm{O}^{*}$ and $\mathrm{HOO}^{*}$, illustrated using the example of the on-top site at a substituted Fe surface atom in $\gamma-\mathrm{NiOOH}(01 \overline{12})$. The binding energies of these species are used to estimate the OER overpotential. b OER activity volcano showing the overpotential as a function of Gibbs free energies of the reaction intermediates. Computed overpotentials are shown for the OER at Ni-Ni bridge and $\mathrm{Fe}$ on-top sites located in pure $\gamma-\mathrm{NiOOH}$ $(01 \overline{12})$ and in $\gamma-\mathrm{NiOOH}(01 \overline{12})$ with Fe surface and subsurface doping, at a $\mathrm{Ni}$ on-top site in pure $\gamma-\mathrm{NiOOH}(01 \overline{12})$, and at $\mathrm{Fe}-\mathrm{Fe}$ bridge sites in pure and Ni-doped $\gamma$-FeOOH(010) $(25 \% \mathrm{Ni}$ in bulk unit cell). Reprinted (adapted) with permission from [47]. Copyright (2020) American Chemical Society
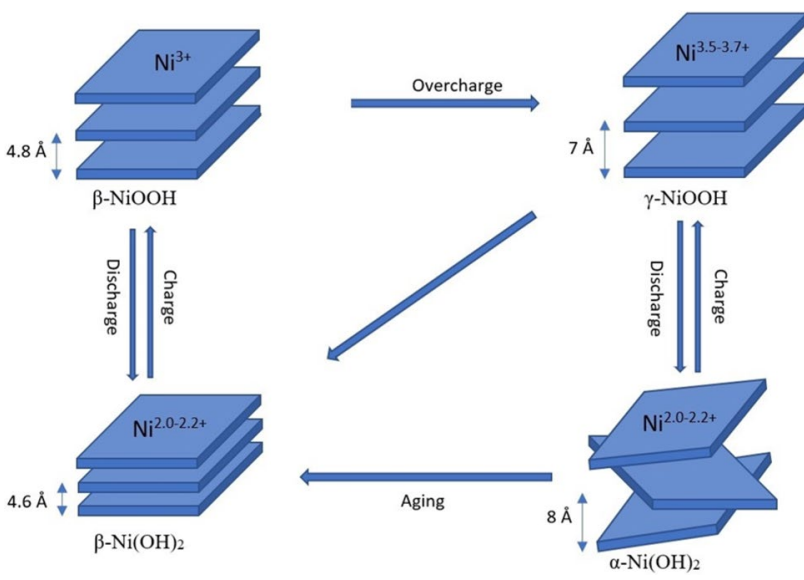

Fig. 5 Bode scheme of the different redox transformations of the $\mathrm{Ni}(\mathrm{OH})_{2} / \mathrm{NiOOH}$ catalyst in alkaline electrolyte

the catalyst, thus once more determination of the active sites was inconclusive.

Even though the pioneering work of Corrigan [41] on the influence of $\mathrm{Fe}$ impurities on the activity of $\mathrm{Ni}(\mathrm{OH})_{2} /$ $\mathrm{NiOOH}$ was known from the 80s, there had been no systematic study on the actual role of $\mathrm{Fe}$ impurities on the activity and probably on the stability of OER catalysts in alkaline environment until the early 2010s'. Trotochaud et al. [60], were among the first to identify the promotional effect of Fe impurities on oxygen electrocatalysis in alkaline electrolytes. Interestingly the authors showed, that both $\beta$ - and $\gamma$-NiOOH phases are poor electrocatalysts for the OER in Fe-free electrolyte with overpotentials higher than $500 \mathrm{mV}$ at $10 \mathrm{~mA} / \mathrm{cm}^{2}$. In this work, the authors focused on the effect of incidental $\mathrm{Fe}$ impurities in the electrolyte on the catalyst performance and concluded that the incorporation of $\mathrm{Fe}$ on $\mathrm{NiOOH}$ is responsible for the catalyst activation, thus showcasing that previous knowledge on the mechanism of Ni-based OER catalysts was compromised by Fe impurities.

We recently showed that Fe impurities in the electrolyte at concentrations as low as $40 \mu \mathrm{g} / \mathrm{L}$ have a huge impact not only on the activity but also on the stability of the $\mathrm{Ni}-\mathrm{Co}_{3} \mathrm{O}_{4}$ catalyst used [61]. Activity was enhanced both after catalyst activation by cycling between 0.7 and $1.6 \mathrm{~V}_{\mathrm{RHE}}$ at $50 \mathrm{mV} / \mathrm{s}$ and after a prolonged electrolysis stress test at $10 \mathrm{~mA} / \mathrm{cm}^{2}$ for $2 \mathrm{~h}$ (Figs. 6, 7a).

Most interestingly, ICP-OES analysis revealed an Fe uptake on the catalyst during prolonged electrolysis and negligible $\mathrm{Ni}$ and Co dissolution (Fig. 7b), compared to the same catalyst treated in purified electrolyte where the amount of $\mathrm{Ni}$ and Co dissolved after the same $2 \mathrm{~h}$ stress test was substantially higher (Fig. 7c). Our data suggest that Fe is only loosely incorporated on the catalyst surface and not in the bulk and is swiftly removed when polarization ends (not shown here). 


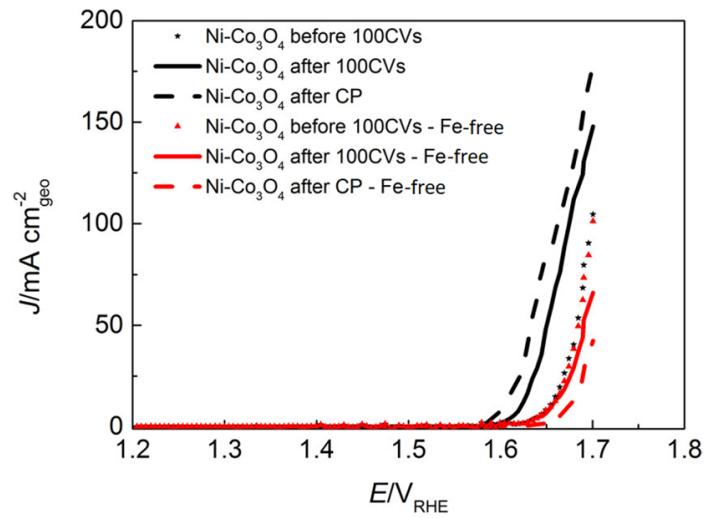

Fig. 6 Activity comparison of the $\mathrm{Ni}-\mathrm{Co}_{3} \mathrm{O}_{4}$ catalyst between 1.2 and $1.7 \mathrm{~V}_{\mathrm{RHE}}$ at $5 \mathrm{mV} \mathrm{s}^{-1}$ scan rate in Fe-contaminated (black) and Fefree (red) $1 \mathrm{M} \mathrm{KOH}$. Reprinted (adapted) with permission from [47]. Copyright (2020) American Chemical Society

Corrigan in his work on a $\mathrm{Ni}(\mathrm{OH})_{2} / \mathrm{NiOOH}$ catalyst, correlated the remarkable activity of the catalyst towards oxygen evolution on the presence of $\mathrm{Fe}$ impurities in the electrolyte and cautioned that future investigations should avoid such pitfalls. In his work, Corrigan tried to explain the resulting boost in activity evidenced by the immense drop of the Tafel slope from 70 to $20-25 \mathrm{mV} / \mathrm{dec}$ for the $\mathrm{Fe}$ doped $\mathrm{Ni}$ catalyst on the amount of $\mathrm{Fe}$ in the electrolyte and a change of the rate determining step from the discharge of hydroxide ions with an expected Tafel slope of a $120 \mathrm{mV} /$ dec to the recombination of oxygen radicals, with a $15 \mathrm{mV} /$ dec slope. This could be one plausible explanation, if the $\mathrm{Fe}$ sites present on the catalyst surface could provide more favorable sites for adsorption of the radical intermediates. In another explanation by Corrigan, he linked the observed activity boost to a conductivity enhancement of the catalyst through the incorporation of $\mathrm{Fe}$ sites. His explanation was based on findings by Lu et al. [56] who had previously suggested that the low conductivity of $\mathrm{Ni}$ oxides can affect the overpotential for oxygen evolution due to so called barrier layer effects [62].

Although NiFe-based oxides are well known to be the most active non-platinum group catalysts for the OER [63, 64], not until the effect of Fe was recognized, most work on Ni catalysts for the OER was focused on correlating catalyst structure to activity and investigating the effect of alloying and/or doping Ni oxides with other metal cations, with $\mathrm{Fe}$ being the most prominent [65-72]. However, direct mediation of Fe present in the electrolyte on electrolytic reactions is something that has always been neglected. Boetcher et al. were among the first to identify the promotional effect of $\mathrm{Fe}$ impurities on oxygen electrocatalysis in alkaline electrolytes and thus introduced a purification methodology for removal of Fe residues from the electrolyte, in order to compare the intrinsic activities
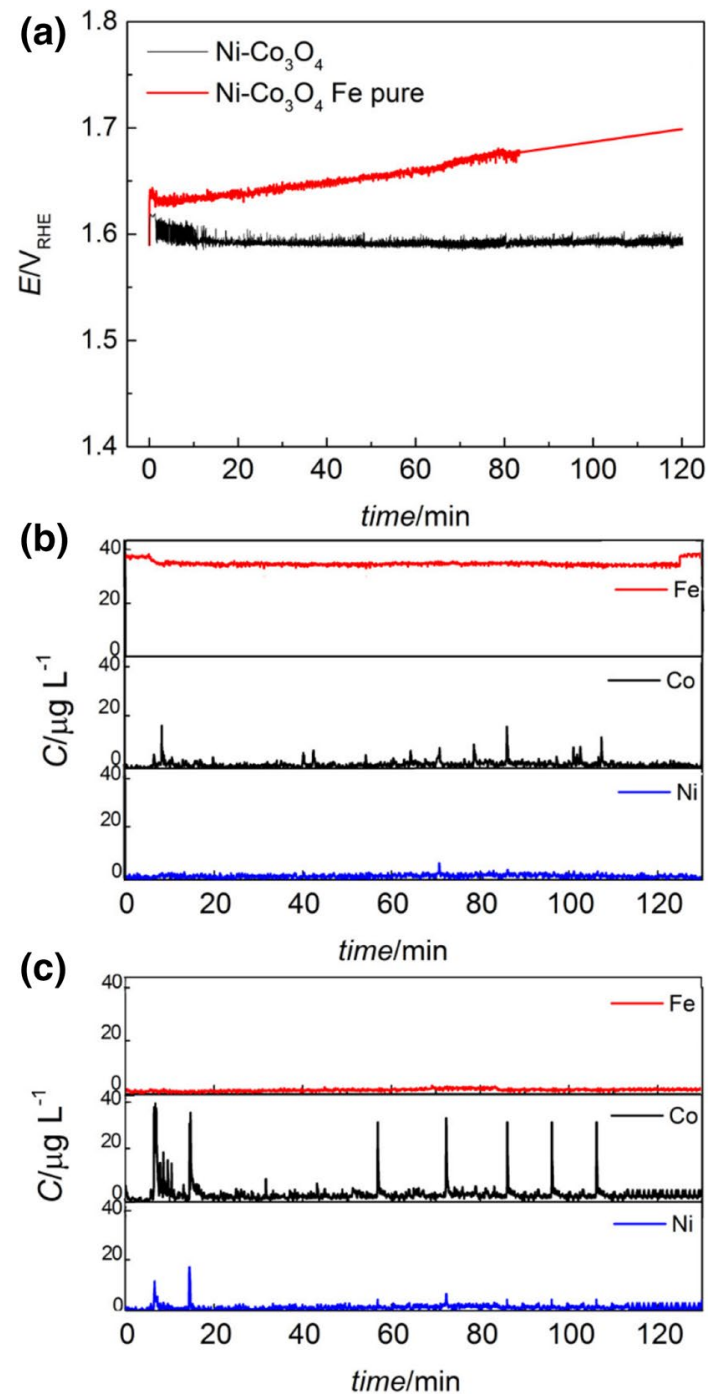

Fig. 7 Chronopotentiometry stress test profiles of the $\mathrm{Ni}-\mathrm{Co}_{3} \mathrm{O}_{4}$ catalyst with and without $\mathrm{Fe}$ in solution at $10 \mathrm{~mA} \mathrm{~cm}{ }^{-2}$ for $2 \mathrm{~h}$. ICP-OES transient analysis of the corrosion products of the $\mathrm{Ni}-\mathrm{Co}_{3} \mathrm{O}_{4}$ catalyst in (b) $1 \mathrm{M} \mathrm{KOH} \mathrm{Fe-contaminated} \mathrm{and} \mathrm{(c)} \mathrm{Fe}$-free $\mathrm{KOH}$ solution. The Fe content of the $\mathrm{KOH}$ solution was monitored Reprinted (adapted) with permission from [61]. Copyright (2020) American Chemical Society

of various catalysts without the inadvertent contribution of Fe. In their work, [60] activity increase after cycling in sub-OER potentials was typically linked to catalyst ageing and the phase transformation of $\alpha-\mathrm{Ni}(\mathrm{OH})_{2}$ to $\beta-\mathrm{Ni}(\mathrm{OH})_{2}$ which up until then had led to the conclusion that the OER activity of $\beta-\mathrm{NiOOH}$ was higher compared to that of $\gamma-\mathrm{NiOOH}$. However, as indicated by Trotochaud et al. and Klaus et al., [72, 73] the increase in OER activity for the $\mathrm{Ni}(\mathrm{OH})_{2} / \mathrm{NiOOH}$ catalyst was linked to inherent presence of $\mathrm{Fe}$ impurities in the commercial $\mathrm{KOH}$ electrolyte. However, the significant activity improvement could not be explained only in terms of conductivity enhancement 
arising from the incorporation of Fe impurities on the catalyst surface. Thus, the authors concluded that the $\mathrm{Fe}$ sites must be the active sites of the reaction.

Additionally, the effect of Co was investigated in order to clarify the reaction mechanism on those ternary alloys. Apparently, alloying Ni with Co enhances activity only by a factor of two compared to $\mathrm{CoO}_{x} \mathrm{H}_{\mathrm{y}}$ catalysts. However, a two to three orders of magnitude greater activity is observed when $\mathrm{Fe}$ is co-deposited or even just spiked in the solution, also showing that Ni-base oxides have a higher affinity towards Fe incorporation compared to Co-based oxides [74, 75].

Likewise, Li et al., [76] and Zhou et al. [77] performed calculations for a $\mathrm{Ni}_{1-\mathrm{x}} \mathrm{Fe}_{\mathrm{x}} \mathrm{OOH}$ and $\mathrm{NiOOH}$ OER catalyst respectively to clarify the role of $\mathrm{Fe}$ and $\mathrm{Ni}$ species. The former concluded that the Fe centers served as the active sites for the reaction, while the latter calculated the Pourbaix diagram of $\mathrm{Ni}$ electrodes and showed that under reaction conditions exist several metastable $\mathrm{NiO}_{x} \mathrm{H}_{y}$ phases while at the same time Fe doping enhances the stability of oxy-hydroxo species (Fig. 8). Therefore, based on their calculations, the authors concluded that when a N-based catalyst is immersed in water, both water molecules and $\mathrm{Fe}$ ions intercalate into the bulk of the electrode, causing the layered structure to exfoliate and subsequently further adsorb on the inner layers. Thus, higher and lower oxidation state $\mathrm{Fe}$ and $\mathrm{Ni}$ ions respectively emerge through the proton transfer between $\mathrm{Fe}$ and $\mathrm{NiOOH}$, with these newly formed $\mathrm{Ni}$ ions being more active than the initial material.

In a similar work from the group of Nocera [44], the observed $\mathrm{Fe}^{3+}$ were responsible for the formation of formal $\mathrm{Ni}^{4+}$ which can be directly correlated to the enhanced activity of the Fe doped $\mathrm{Ni}$ oxide system studied and thus they were considered as the active sites, while Chen et. al [78] could not find sufficient evidence from Mossbauer spectroscopy that the resulted $\mathrm{Fe}^{4+}$ sites produced during OER were enough to be considered as the active sites.

In a different approach Xiao et al. [79], used DFT calculations to determine the mechanism for OER, including the kinetics of $\mathrm{O}-\mathrm{O}$ coupling on pure and $\mathrm{Fe}$-doped $\mathrm{NiOOH}$ catalysts. The authors reported the formation of an active $\mathrm{O}$ radical species and the subsequent $\mathrm{O}-\mathrm{O}$ coupling, thus showcasing that pure $\mathrm{NiOOH}$ is a poor OER catalyst because of its inability to produce the $\mathrm{O}$ radical, in contrast to the $\mathrm{Ni}$ Fe catalyst which due to the synergy between $\mathrm{Ni}$ and $\mathrm{Fe}$, the high spin $\mathrm{Fe}^{4+}$ can stabilize the $\mathrm{O}$ radical by an exchange interaction, while $\mathrm{Ni}^{4+}$ catalyzes the $\mathrm{O}-\mathrm{O}$ coupling. This synergy is key for driving the reaction.

Diaz-Moralles investigated the doping effect of other metals on a NiMOOH catalysts with $\mathrm{M}=\mathrm{Fe}, \mathrm{Cr}$ and $\mathrm{Mn}$ having a positive effect while $\mathrm{Co}, \mathrm{Cu}$ and $\mathrm{Zn}$ on the contrary had a deleterious effect, which also comes into contrast with previous studies which showed that Co actually has a positive effect [80]. Their DFT calculations revealed that in the cases of $\mathrm{Fe}$ and $\mathrm{Mn}$, those metals are expected to be the active sites responsible for the OER activity enhancement in contrast to $\mathrm{Cr}$ which although has a positive effect on activity upon doping the $\mathrm{NiOOH}$ catalyst, it does not act as the active site, but Ni does instead.

To further investigate the effect of Fe on transition metalbased alloy oxide catalysts [81, 82] the group of Boetcher used $\mathrm{MO}_{\mathrm{x}} \mathrm{H}_{\mathrm{y}}$ catalysts with certain $\mathrm{Fe}$ amount spiked into the solution and eliminating the effects of Fe impurities in the electrolyte, conductivity and confounding surface area (Fig. 9). It was firstly shown that when $\mathrm{Ni}$ or $\mathrm{Co}$ are added to Fe-free $\mathrm{CoO}_{x} \mathrm{H}_{y}$ and $\mathrm{NiO}_{\mathrm{x}} \mathrm{H}_{\mathrm{y}}$ catalysts respectively they have only a small effect on activity due to conductivity enhancement, compared to the more impactful Fe spiking, suggesting a small synergistic effect between $\mathrm{Ni}$ and $\mathrm{Co}$. When $\mathrm{Fe}$ is spiked it is not incorporated into the catalyst bulk but
Fig. 8 Pourbaix diagrams with and without Fe doping calculated by HSE06. Doping reduces the formation energies of $\mathrm{Ni}-\mathrm{O}$ compounds and stabilizes the electrodes under reaction conditions. Figures on the right show the configurations of most stable undoped and Fe-doped nickel (oxy)hydroxide compounds from high potential to low potential. Reprinted (adapted) with permission from [77]. Copyright (2020) American Chemical Society
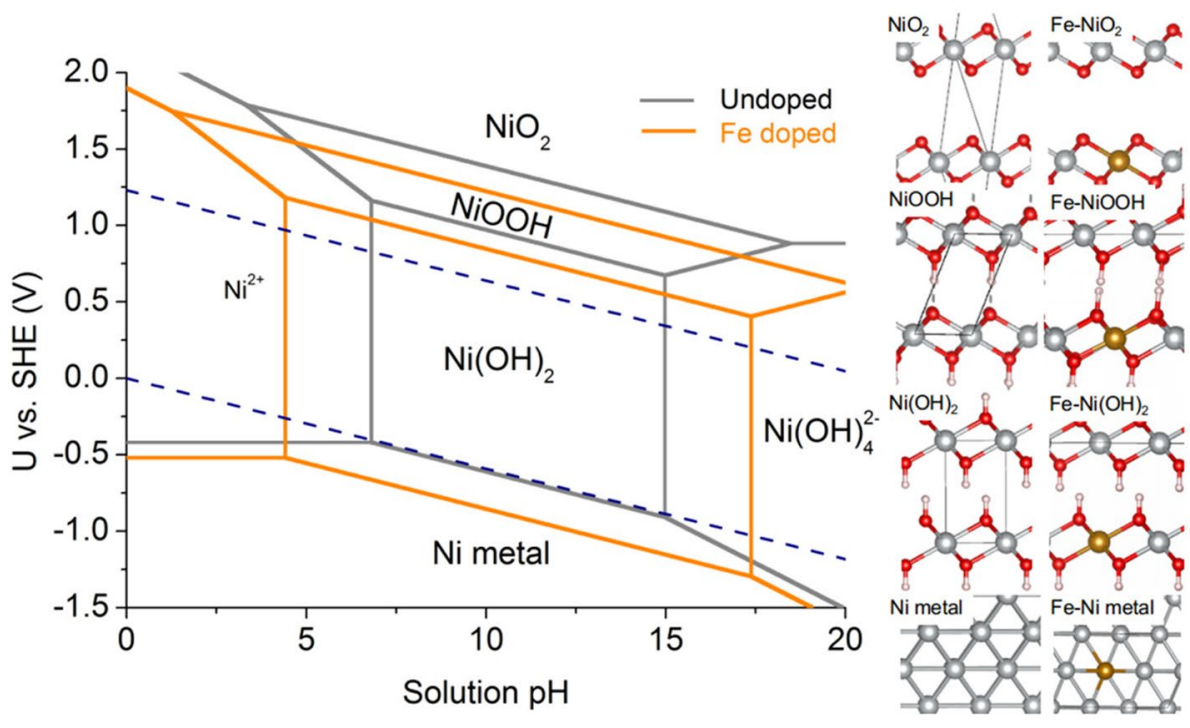


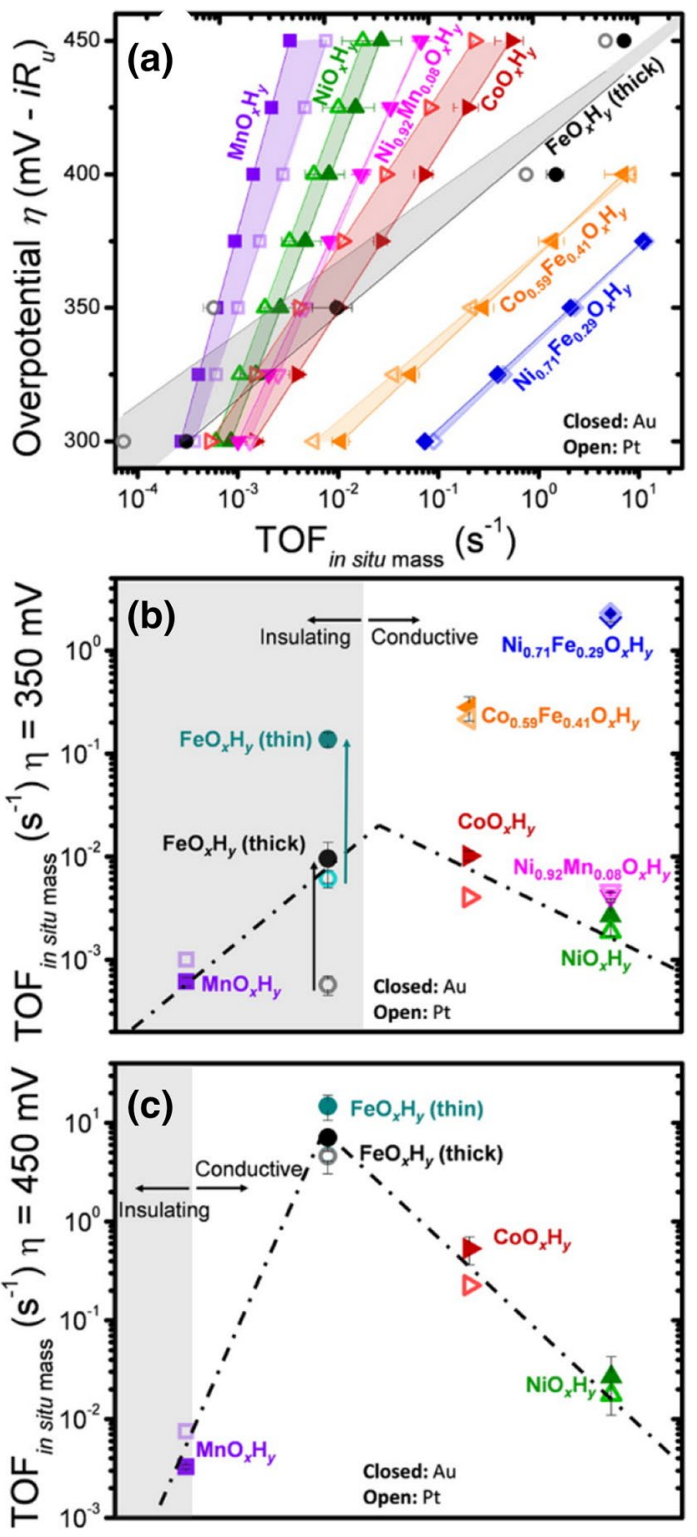

Fig. 9 Activity analysis (a) as a function of overpotential, b at $\eta=350 \mathrm{mV}$, and $\mathbf{c}$ at $\eta=450 \mathrm{mV}$. The catalysts are synthesized by electrodeposition as (oxy)hydroxides on Au (closed symbols) and $\mathrm{Pt}$ (open symbols) microbalance electrodes and measured in triplicate for those on Au. (Some error bars are smaller than the symbols.) Compositions listed in (b) and (c) are ordered based on the atomic number of the host/primary cation. The fit lines and shading in (a) were added to make trends clear. The dotted lines in (b) and (c) are to guide the eye. Film masses were $8-12 \mu \mathrm{g} \mathrm{cm}^{-2}$ for all films except the thin $\mathrm{FeOxHy}$, which was 0.5 to $1.0 \mu \mathrm{g} \mathrm{cm}^{-2}$. Reprinted (adapted) with permission from [81]. Copyright (2020) American Chemical Society

most probably only on the catalyst defects and edges as indicated by the more negative oxidation peak shift compared to a catalyst where Fe was co-deposited, although in both cases the activity was similar. However, as data suggested the affinity of $\mathrm{Fe}$ incorporation on the Ni-based catalysts compared to the Co-ones was the contributing factor for the superior activity of the former.

Finally, Markovic et al. in a similar manner to the previous work, tried to identify the active sites on different $\mathrm{MO}_{\mathrm{x}} \mathrm{H}_{\mathrm{y}}(\mathrm{M}=\mathrm{Ni}, \mathrm{Co}, \mathrm{Fe}, \mathrm{Cu}, \mathrm{Ti}, \mathrm{Mn}, \mathrm{Cr}$ and $\mathrm{V})$ catalysts in $\mathrm{Fe}$-free and $\mathrm{Fe}$-containing electrolytes, suggesting that Fe plays the role of the surface active sites for the reaction, but not in a static/stable state that it has been for long thought to be, but otherwise in a more dynamic/meta-stable state. The number of these sites is dependent on the balancing of the dissolution and redeposition rates of $\mathrm{Fe}$ on the host $\mathrm{MO}_{\mathrm{x}} \mathrm{H}_{\mathrm{y}}$ material and the affinity of the host metal $\mathrm{M}$ to strongly interact with $\mathrm{Fe}$, when $\mathrm{Fe}$ is either co-deposited on the $\mathrm{MO}_{\mathrm{x}} \mathrm{H}_{\mathrm{y}}$ catalysts or simply spiked in the electrolyte [83].

From all the single metal $\mathrm{MO}_{\mathrm{x}} \mathrm{H}_{\mathrm{y}}$ catalysts investigated, $\mathrm{NiO}_{x} \mathrm{H}_{y}$ shows the highest affinity to attract $\mathrm{Fe}$, followed by $\mathrm{Co}, \mathrm{Fe}, \mathrm{Mn}, \mathrm{Cr}, \mathrm{V}$ and Ti. In Fe-free $0.1 \mathrm{M} \mathrm{KOH}$ catalytic activity follows the order: $\mathrm{FeO}_{x} \mathrm{H}_{y}>\mathrm{CoO}_{x} \mathrm{H}_{y}>\mathrm{NiO}_{x} \mathrm{H}_{y}$, with stability having the exact opposite trend $\mathrm{FeO}_{\mathrm{x}} \mathrm{H}_{\mathrm{y}}<\mathrm{CoO}_{\mathrm{x}} \mathrm{H}_{\mathrm{y}}<\mathrm{NiO}_{\mathrm{x}} \mathrm{H}_{\mathrm{y}}$. However, when $0.1 \mathrm{ppm}$ of $\mathrm{Fe}$ was spiked in the solution which resulted in a certain amount of Fe to be deposited on the catalyst surface, the activity trend gets reversed but once again the stability of the now $\mathrm{Fe}$ containing catalysts remains the same as in the non-Fe containing solution: $\mathrm{Fe}-\mathrm{FeO}_{\mathrm{x}} \mathrm{H}_{\mathrm{y}}<\mathrm{Fe}-\mathrm{CoO}_{\mathrm{x}} \mathrm{H}_{\mathrm{y}}<\mathrm{Fe}-\mathrm{NiO}_{\mathrm{x}} \mathrm{H}_{\mathrm{y}}$. By doping the $\mathrm{NiO}_{x} \mathrm{H}_{y}$ catalyst with other $3 \mathrm{~d}$ transition metals the authors were able to further tune the adsorption energy of $\mathrm{Fe}$ on the catalysts and further improve catalytic activity.

Interestingly, $\mathrm{CuO}_{\mathrm{x}} \mathrm{H}_{\mathrm{y}}$ has even higher Fe adsorption energy than $\mathrm{Ni}$ suggesting that $\mathrm{CuO}_{x} \mathrm{H}_{y}$ could potentially be a better candidate for an OER catalyst, however its high dissolution rate prevents its potential practical use. Thus, doping $\mathrm{Ni}$ with $\mathrm{Cu}$ proved to consolidate the individual properties of $\mathrm{NiO}_{x} \mathrm{H}_{y}$ and $\mathrm{CuO}_{\mathrm{x}} \mathrm{H}_{\mathrm{y}}$, that is, high stability, high Fe adsorption energy and in the end superior catalytic activity than any other $\mathrm{M}$-doped $\mathrm{NiO}_{\mathrm{x}} \mathrm{H}_{\mathrm{y}}$ studied by the authors. These findings suggest actually that the saturation coverage of $\mathrm{Fe}$ on a given $\mathrm{MO}_{\mathrm{x}} \mathrm{H}_{\mathrm{y}}$ catalyst, could be a more relevant activity descriptor than the $\mathrm{M}-\mathrm{O}$ adsorption energy (Sabatier principle).

\section{Summary}

To sum up, we have shown that the intrinsic activity in the case of Ni-based oxide catalysts, by the accidental or onpurpose addition of $\mathrm{Fe}$ impurities in the electrolyte can be orders of magnitude higher compared to Fe-free electrolyte/ catalysts. One can only wonder how such trace amounts of impurities can have such a significant effect on the activity and stability of certain types of catalysts. In many cases, even the slightest amount of metal impurities in the electrolyte or in the bulk of the catalyst may not only greatly boost 
but also plummet a catalyst's performance, only to conclude that perhaps impurities really run the reaction in many cases, with the 'catalysts' just playing the role of a vessel carrying those impurities or otherwise catalysts in such cases.

That means, in order to run proper electrochemical experiments, we need to eliminate all those factors that can lead to false conclusions, but more importantly it opens new avenues of research into understanding the nature of interaction between electrode and impurities/ions at the interface. Afterall, proper electrochemistry really relies on clean experiments which however is sometimes unfortunately neglected, not on purpose but because in many cases we cannot know. Unless thoroughly investigated, the effect of parameters often presumed to be inconsequential, such as trace amounts of certain metals present in the electrolyte or the inclusion of certain metal precursors during catalyst preparation, as well as residues from cell cleaning, ought not to be assumed to be passive.

A characteristic example is the effect of Fe on Ni-based catalysts. Even though the OER activity of such catalysts is apparently higher compared to Co-based oxides, the intrinsic activity of the former decreases significantly upon removal of Fe impurities from the electrolyte leading to a lot lower OER activity than that of Co oxides. Just a trace of Fe can significantly lower the OER reaction overpotential, while at the same time cyclic voltammetry shows a significant positive shift in oxidation and reduction potentials of $\mathrm{Ni}$ species present in the catalyst, which change with increasing amount of Fe.

The precise role of Fe impurities has long been debated with conflicting explanations. The prevailing theories are that incorporation of $\mathrm{Fe}$ on the catalyst surface (very improbable to affect the bulk too) enhances the conductivity of $\mathrm{NiOOH}$, or that a new dual metal active site $\mathrm{Ni}-\mathrm{FeOOH}$ is formed, for which an electronic effect is responsible for the remarkable activity enhancement. More recently, it was also proposed that $\mathrm{Fe}$ impurities are the active sites themselves and the underlying catalyst only plays the role of a conducting medium. Another possibility could be the formation of an extremely thin layer of $\mathrm{Fe}$ in the outer Helmholtz plane which enhances charge transfer by facilitating electron tunneling towards the catalyst, since it has also been shown that the addition of other elements other than $\mathrm{Fe}$ in the electrolyte can have a similar effect. All this is still however not understood and to a great extent speculative, which means that a proper understanding of phenomena as complex as these could potentially have a huge impact on future design of catalysts and experimental setups.

Finally, we have presented different transition metalbased catalyst activation mechanisms, where catalyst activity and more precisely catalyst active sites have been classified in terms of catalyst support, catalyst surface conductivity, mixed valence oxidation state of the catalyst material, differences in $\mathrm{M}-\mathrm{O}$ bond length and strength and in terms of impurities. In the latter case, $\mathrm{Fe}$ has been the predominant metal impurity with a significant influence on the catalytic properties. All the above lead to the conclusion that understanding which are the OER active sites of transition metalbased catalysts and the actual effect of $\mathrm{Fe}$ impurities are still poorly explained.

\section{Perspective}

Water electrolysis and in particular OER can be very challenging due to sluggish kinetics and the multi-step/multiple intermediates involved in comparison to the hydrogen evolution reaction (HER) which is a much faster process. However, catalyst materials and undoubtedly factors such as catalyst stability/dissolution also play a crucial role on the reaction efficiency. Water electrolysis has proved to be a very impactful reaction in the energy era of our time especially after the realization that oxygen evolution reaction catalysts are of the outmost importance not only for water oxidation but also for metal-air and regenerative fuel cells related processes. As such an OER catalyst of high performance can serve in a multitude of purposes.

As far as the OER is concerned, two types of catalysts have been used for many decades. Ir- and Ni-based oxides are the most common materials of high activity and stability for acidic and alkaline environment respectively. The large cost and low abundance of Ir-based catalysts and common corrosion problems prevalent in PEM electrolyzers compared to their Ni counterparts used in alkaline water electrolysis, make the latter more favorable as water oxidation catalysts for the long term.

However, one needs to realize that the choice of the proper catalyst requires thorough investigation of the preparation method, catalyst structure/morphology, catalyst conductivity, the effect of catalyst support, the electrolyte effect and most importantly the effect of impurities and/or dopants in the electrolyte, and the catalyst material itself. Catalyst intrinsic conductivity in particular is a very important material property that greatly impacts apparent activity, however, this can be boosted via dopants in the material, or by supporting the catalyst on carbon-based supports or noble metals, which in the former case also greatly increases the catalyst surface area typically by introducing micro-porosity into the catalyst, another important key factor for reactivity.

From this point of view, there are still many aspects that need to be thoroughly investigated before scaling-up and commercializing water electrolysis can be realized at a cost-effective level. At first, a complete understanding of how morphology and structure of catalysts affect activity and stability is key to designing new materials with controllable size, shape and morphology which can affect 
reaction selectivity. In the case of OER, during the last few decades there has been a swift change towards nanomaterials due to their favorable size which leads to extremely high available surface to catalyze the reaction. However, even those efforts lack a proper understanding of how for example nanoparticle shape and surface area affect the exposed active sites.

One of the most important aspects of electrochemistry still remains the full understanding of a reaction's mechanism, which is of outmost importance in order not only to enhance the reaction rates by diminishing reaction barriers but also to avoid unwanted side effects and side-products like hydrogen peroxide. Even though the theoretical background on OER mechanism is immense, going back to fundamental understanding of certain processes can still help bridging this knowledge with the catalyst morphology and electrochemical conditions. Such a broad knowledge of all these processes is necessary not only to improve activity but also stability, which is far more important, since an active but unstable catalyst, typical example for the OER is $\mathrm{RuO}_{2}$, is unimportant. A catalyst that can sacrifice some activity for the sake of stability is far more desirable. For this reason, novel materials, such $\mathrm{Ni}$-borides and phosphides have only recently shown very promising catalytic properties. Ni-phosphides in particular, due to leaching of phosphorus during water electrolysis become considerably more active, most likely due to surface area enhancement, a very interesting path to investigate.

Another important aspect, that still needs to be understood is reactions kinetics and mass transport of reactants and products not only in laboratory conditions and half-cell reactions but also in commercial systems under realistic conditions, where more complex phenomena related to catalyst loading and bubble formation and removal are relevant to be investigated.

Acknowledgements The authors would like to acknowledge Max Planck Society and the MAXNET Energy consortium for the financial support.

Funding Open Access funding enabled and organized by Projekt DEAL..

\section{Compliance with Ethical Standards}

Conflict of interest The authors declare no conflict of interest.

Open Access This article is licensed under a Creative Commons Attribution 4.0 International License, which permits use, sharing, adaptation, distribution and reproduction in any medium or format, as long as you give appropriate credit to the original author(s) and the source, provide a link to the Creative Commons licence, and indicate if changes were made. The images or other third party material in this article are included in the article's Creative Commons licence, unless indicated otherwise in a credit line to the material. If material is not included in the article's Creative Commons licence and your intended use is not permitted by statutory regulation or exceeds the permitted use, you will need to obtain permission directly from the copyright holder. To view a copy of this licence, visit http://creativecommons.org/licenses/by/4.0/.

\section{References}

1. Krasil'shchikov AN (1963) Intermediate stages in the anodic evolution of oxygen. Zh Fiz Khim 37(531):531-537

2. Matsumoto Y, Sato E (1986) Electrocatalytic properties of transition metal oxides for oxygen evolution reaction. Mater Chem Phys 14(5):397-426

3. Bockris JOM (1975) On methods for the large-scale production of hydrogen from water. In: Veziroğlu TN (ed) Hydrogen energy: part A. Springer, Boston, pp 371-403

4. Spanos I, Auer AA, Neugebauer S et al (2017) Standardized benchmarking of water splitting catalysts in a combined electrochemical flow cell/inductively coupled plasma-optical emission spectrometry (ICP-OES) setup. ACS Catal 7(6):3768-3778

5. Nuttall LJ, Fickett AP, Titterington WA (1975) Hydrogen generation by solid polymer electrolyte water electrolysis. In: Veziroğlu TN (ed) Hydrogen energy: part A. Springer, Boston, pp 441-455

6. Trasatti S (1980) Electrocatalysis by oxides - Attempt at a unifying approach. J Electroanal Chem Interfacial Electrochem 111(1):125-131

7. Damjanovic A, Dey A, Bockris JOM (1966) Electrode kinetics of oxygen evolution and dissolution on $\mathrm{Rh}$, Ir, and Pt-Rh alloy electrodes. J Electrochem Soc 113(7):739

8. Pfeifer V, Jones TE, Velasco Vélez JJ et al (2016) The electronic structure of iridium and its oxides. Surf Interface Anal 48(5):261-273

9. Reier T, Teschner D, Lunkenbein T et al (2014) Electrocatalytic oxygen evolution on iridium oxide: uncovering catalyst-substrate interactions and active iridium oxide species. J Electrochem Soc 161(9):F876-F882

10. Pfeifer V, Jones TE, Velasco Vélez JJ et al (2017) In situ observation of reactive oxygen species forming on oxygen-evolving iridium surfaces. Chem Sci 8(3):2143-2149

11. Kasian O, Geiger S, Stock P et al (2016) On the origin of the improved ruthenium stability in $\mathrm{RuO} 2-\mathrm{IrO} 2$ mixed oxides. J Electrochem Soc 163(11):F3099-F3104

12. Cherevko S, Geiger S, Kasian $\mathrm{O}$ et al (2016) Oxygen and hydrogen evolution reactions on $\mathrm{Ru}, \mathrm{RuO} 2, \mathrm{Ir}$, and $\mathrm{IrO} 2$ thin film electrodes in acidic and alkaline electrolytes: a comparative study on activity and stability. Catal Today 262:170-180

13. Danilovic N, Subbaraman R, Chang KC et al (2014) Activitystability trends for the oxygen evolution reaction on monometallic oxides in acidic environments. J Phys Chem Lett 5(14):2474-2478

14. Kötz R, Lewerenz HJ, Stucki S (1983) XPS studies of oxygen evolution on $\mathrm{Ru}$ and $\mathrm{RuO} 2$ anodes. J Electrochem Soc 130(4):825-829

15. Kötz R, Neff H, Stucki S (1984) Anodic iridium oxide films: XPS-studies of oxidation state changes and. J Electrochem Soc 131(1):72-77

16. Goodenough JB (1971) Metallic oxides. Prog Solid State Chem 5:145-399

17. Mayrhofer KJJ, Wiberg GKH, Arenz M (2008) Impact of glass corrosion on the electrocatalysis on Pt electrodes in alkaline electrolyte. J Electrochem Soc 155(1):P1

18. Kwon Y, Birdja Y, Spanos I et al (2012) Highly selective electrooxidation of glycerol to dihydroxyacetone on platinum in the presence of bismuth. ACS Catal 2(5):759-764 
19. Pumera M, Iwai H (2009) Metallic impurities within residual catalyst metallic nanoparticles are in some cases responsible for "electrocatalytic" effect of carbon nanotubes. Chem Asian J 4(4):554-560

20. Ullman AM, Liu Y, Huynh M et al (2014) Water oxidation catalysis by Co(II) impurities in Co(III) $4 \mathrm{O} 4$ cubanes. J Am Chem Soc 136(50):17681-17688

21. Surendranath Y, Lutterman DA, Liu Y et al (2012) Nucleation, growth, and repair of a cobalt-based oxygen evolving catalyst. J Am Chem Soc 134(14):6326-6336

22. Bockris JOM, McHardy J (1973) Electrocatalysis of oxygen reduction by sodium tungsten bronze. J Electrochem Soc 120(1):61

23. Shin S, Kim J, Park S et al (2019) Changes in the oxidation state of Pt single-atom catalysts upon removal of chloride ligands and their effect for electrochemical reactions. Chem Commun 55(45):6389-6392

24. Schmidt TJ, Paulus UA, Gasteiger HA et al (2001) The oxygen reduction reaction on a $\mathrm{Pt} /$ carbon fuel cell catalyst in the presence of chloride anions. J Electroanal Chem 508(1):41-47

25. Strmcnik D, Escudero-Escribano M, Kodama K et al (2010) Enhanced electrocatalysis of the oxygen reduction reaction based on patterning of platinum surfaces with cyanide. Nat Chem 2(10):880-885

26. Katsounaros I, Schneider WB, Meier JC et al (2013) The impact of spectator species on the interaction of $\mathrm{H} 2 \mathrm{O} 2$ with platinum implications for the oxygen reduction reaction pathways. Phys Chem Chem Phys 15(21):8058-8068

27. Calle-Vallejo F, Koper MTM (2013) Theoretical considerations on the electroreduction of $\mathrm{CO}$ to $\mathrm{C} 2$ species on $\mathrm{Cu}(100)$ electrodes. Angew Chem Int Ed 52(28):7282-7285

28. Hatsukade T, Kuhl KP, Cave ER et al (2014) Insights into the electrocatalytic reduction of $\mathrm{CO} 2$ on metallic silver surfaces. Phys Chem Chem Phys 16(27):13814-13819

29. Hori Y, Wakebe H, Tsukamoto T et al (1994) Electrocatalytic process of $\mathrm{CO}$ selectivity in electrochemical reduction of $\mathrm{CO} 2$ at metal electrodes in aqueous media. Electrochim Acta 39(11):1833-1839

30. Kedzierzawski P, Augustynski J (1994) Poisoning and activation of the gold cathode during electroreduction of $\mathrm{CO} 2$. J Electrochem Soc 141(5):L58-L60

31. Kostecki R, Augustynski J (1994) Electrochemical reduction of $\mathrm{CO} 2$ at an activated silver electrode. Berichte der Bunsengesellschaft für physikalische Chemie 98(12):1510-1515

32. Kuhl KP, Cave ER, Abram DN et al (2012) New insights into the electrochemical reduction of carbon dioxide on metallic copper surfaces. Energy Environ Sci 5(5):7050-7059

33. Montoya JH, Peterson AA, Nørskov JK (2013) Insights into $\mathrm{C}-\mathrm{C}$ coupling in $\mathrm{CO} 2$ electroreduction on copper Eeectrodes. ChemCatChem 5(3):737-742

34. Nie X, Esopi MR, Janik MJ et al (2013) Selectivity of CO2 Reduction on copper electrodes: the role of the kinetics of elementary steps. Angew Chem Int Ed 52(9):2459-2462

35. Peterson AA, Nørskov JK (2012) Activity descriptors for CO2 electroreduction to methane on transition-metal catalysts. J Phys Chem Lett 3(2):251-258

36. Sreekanth N, Phani KL (2014) Selective reduction of CO2 to formate through bicarbonate reduction on metal electrodes: new insights gained from SG/TC mode of SECM. Chem Commun 50(76): 11143-11146

37. Masa J, Zhao A, Xia W et al (2013) Trace metal residues promote the activity of supposedly metal-free nitrogen-modified carbon catalysts for the oxygen reduction reaction. Electrochem Commun 34:113-116

38. Morales DM, Masa J, Andronescu C et al (2017) Promotional effect of $\mathrm{Fe}$ impurities in graphene precursors on the activity of
$\mathrm{MnOX/graphene} \mathrm{electrocatalysts} \mathrm{for} \mathrm{the} \mathrm{oxygen} \mathrm{evolution} \mathrm{and}$ oxygen reduction reactions. ChemElectroChem 4(11):2835-2841

39. Deng J, Ren P, Deng D et al (2014) Highly active and durable non-precious-metal catalysts encapsulated in carbon nanotubes for hydrogen evolution reaction. Energy Environ Sci 7(6):1919-1923

40. Banks CE, Crossley A, Salter C, Compton RG et al (2006) Carbon nanotubes contain metal impurities which are responsible for the "electrocatalysis" seen at some nanotube-modified electrodes. Angew Chem Int Ed 45(16):2533-2537

41. Corrigan DA (1987) The catalysis of the oxygen evolution reaction by iron impurities in thin film nickel oxide electrodes. J Electrochem Soc 134(2):377-384

42. Bockris JOM, Otagawa T (1984) The electrocatalysis of oxygen evolution on perovskites. J Electrochem Soc 131(2):290-302

43. Trasatti S (1984) Electrocatalysis in the anodic evolution of oxygen and chlorine. Electrochim Acta 29(11):1503-1512

44. Li N, Bediako DK, Hadt RG et al (2017) Influence of iron doping on tetravalent nickel content in catalytic oxygen evolving films. Proc Natl Acad Sci 114(7):1486

45. Görlin M, Chernev P, Ferreira de Araújo J et al (2016) Oxygen evolution reaction dynamics, faradaic charge efficiency, and the active metal redox states of $\mathrm{Ni}-\mathrm{Fe}$ oxide water splitting electrocatalysts. J Am Chem Soc. 138(17):5603-5614

46. Louie MW, Bell AT (2013) An investigation of thin-film Ni-Fe oxide catalysts for the electrochemical evolution of oxygen. J Am Chem Soc 135(33):12329-12337

47. Friebel D, Louie MW, Bajdich M et al (2015) Identification of highly active $\mathrm{Fe}$ sites in $(\mathrm{Ni}, \mathrm{Fe}) \mathrm{OOH}$ for electrocatalytic water splitting. J Am Chem Soc 137(3):1305-1313

48. Ahn HS, Bard AJ (2016) Surface interrogation scanning electrochemical microscopy of Ni1-xFexOOH $(0<\mathrm{x}<0.27)$ oxygen evolving catalyst: kinetics of the "fast" iron sites. J Am Chem Soc 138(1):313-318

49. Bode H, Dehmelt K, Witte J (1966) Zur kenntnis der nickelhydroxidelektrode-I.Über das nickel (II)-hydroxidhydrat. Electrochim Acta 11(8):1079-1087

50. Kostecki R, McLarnon F (1997) Electrochemical and in situ Raman spectroscopic characterization of Nickel Hydroxide Electrodes: I. Pure Nickel Hydroxide. J Electrochem Soc 144(2):485-493

51. Merrill MD, Dougherty RC (2008) Metal oxide catalysts for the evolution of $\mathrm{O} 2$ from H2O. J Phys Chem C 112(10):3655-3666

52. Godwin IJ, Lyons MEG (2013) Short communication. Electrochem Commun 32:39-42

53. Oliva P, Leonardi J, Laurent JF et al (1982) Review of the structure and the electrochemistry of nickel hydroxides and oxyhydroxides. J Power Sour 8(2):229-255

54. Desilvestro J, Corrigan DA, Weaver MJ (1988) Characterization of redox states of nickel hydroxide film electrodes by in situ surface Raman spectroscopy. J Electrochem Soc 135(4):885-892

55. Michael EG, Lyons MPB (2008) The oxygen evolution reaction on passive oxide covered transition metal electrodes in aqueous alkaline solution Part 1-Nickel. Int J Electrochem Sci 3:1386-1424

56. Lu PWT, Srinivasan S (1978) Electrochemical-ellipsometric studies of oxide film formed on nickel during oxygen evolution. J Electrochem Soc 125(9):1416-1422

57. Cappadonia M, Divisek J, von der Heyden T et al (1994) Oxygen evolution at nickel anodes in concentrated alkaline solution. Electrochim Acta 39(11):1559-1564

58. Wehrens-Dijksma M, Notten PHL (2006) Electrochemical Quartz Microbalance characterization of $\mathrm{Ni}(\mathrm{OH}) 2$-based thin film electrodes. Electrochim Acta 51(18):3609-3621

59. Yeo BS, Bell AT (2012) In situ Raman study of nickel oxide and gold-supported nickel oxide catalysts for the electrochemical evolution of oxygen. J Phys Chem C 116(15):8394-8400 
60. Trotochaud L, Young SL, Ranney JK et al (2014) Nickel-iron oxyhydroxide oxygen-evolution electrocatalysts: the role of intentional and incidental iron incorporation. J Am Chem Soc 136(18):6744-6753

61. Spanos I, Tesch MF, Yu M et al (2019) Facile protocol for alkaline electrolyte purification and its influence on a Ni-Co oxide catalyst for the oxygen evolution reaction. ACS Catal 9(9):8165-8170

62. Meyer RE (1960) Cathodic processes on passive zirconium. J Electrochem Soc 107(10):847

63. Corrigan DA (1989) Hydrogen generator having a low oxygen overpotential electrode. US Patent 4,882,024

64. Corrigan DA, Bendert RM (1989) Effect of coprecipitated metal ions on the electrochemistry of nickel hydroxide thin films: cyclic voltammetry in 1M KOH. J Electrochem Soc 136(3):723-728

65. Singh RN, Pandey JP, Anitha KL (1993) Preparation of electrodeposited thin films of nickel-iron alloys on mild steel for alkaline water electrolysis. Part I: studies on oxygen evolution. Int J Hydrogen Energy 18(6):467-473

66. Hu C-C, Wu Y-R (2003) Bipolar performance of the electroplated iron-nickel deposits for water electrolysis. Mater Chem Phys 82(3):588-596

67. Li X, Walsh FC, Pletcher D (2011) Nickel based electrocatalysts for oxygen evolution in high current density, alkaline water electrolysers. Phys Chemy Chem Phys 13(3):1162-1167

68. Landon J, Demeter E, İnoğlu N et al (2012) Spectroscopic characterization of mixed $\mathrm{Fe}-\mathrm{Ni}$ oxide electrocatalysts for the oxygen evolution reaction in alkaline electrolytes. ACS Catal 2(8):1793-1801

69. Miller EL, Rocheleau RE (1997) Electrochemical behavior of reactively sputtered iron-doped nickel oxide. J Electrochem Soc 144(9):3072-3077

70. Gong M, Li Y, Wang H et al (2013) An advanced Ni-Fe layered double hydroxide electrocatalyst for water oxidation. J Am Chem Soc 135(23):8452-8455

71. McCrory CCL, Jung S, Peters JC et al (2013) Benchmarking heterogeneous electrocatalysts for the oxygen evolution reaction. J Am Chem Soc 135(45):16977-16987

72. Trotochaud L, Ranney JK, Williams KN et al (2012) Solution-cast metal oxide thin film electrocatalysts for oxygen evolution. J Am Chem Soc 134(41):17253-17261

73. Klaus S, Cai Y, Louie MW et al (2015) Effects of Fe electrolyte impurities on $\mathrm{Ni}(\mathrm{OH}) 2 / \mathrm{NiOOH}$ structure and oxygen evolution activity. J Phys Chem C 119(13):7243-7254
74. Stevens MB, Trang CDM, Enman LJ et al (2017) Reactive Fe-sites in $\mathrm{Ni} / \mathrm{Fe}(\mathrm{Oxy})$ hydroxide are responsible for exceptional oxygen electrocatalysis activity. J Am Chem Soc 139(33):11361-11364

75. Zhang T, Nellist MR, Enman LJ et al (2019) Modes of Fe incorporation in $\mathrm{Co}-\mathrm{Fe}(\mathrm{Oxy})$ hydroxide oxygen evolution electrocatalysts. Chemsuschem 12(9):2015-2021

76. Li Y-F, Selloni A (2014) Mechanism and activity of water oxidation on selected surfaces of pure and Fe-doped NiOx. ACS Catal 4(4):1148-1153

77. Zhou Y, López N (2020) The role of Fe species on NiOOH in oxygen evolution reactions. ACS Catal 10(11):6254-6261

78. Chen JY, Dang L, Liang H et al (2015) Operando analysis of $\mathrm{NiFe}$ and $\mathrm{Fe}$ oxyhydroxide electrocatalysts for water oxidation: detection of Fe4+ by Mössbauer spectroscopy. J Am Chem Soc 137(48):15090-15093

79. Xiao H, Shin H, Goddard WA (2018) Synergy between Fe and $\mathrm{Ni}$ in the optimal performance of $(\mathrm{Ni}, \mathrm{Fe}) \mathrm{OOH}$ catalysts for the oxygen evolution reaction. Proc Natl Acad Sci 115(23):5872

80. Diaz-Morales O, Ledezma-Yanez I, Koper MTM et al (2015) Guidelines for the rational design of Ni-based double hydroxide electrocatalysts for the oxygen evolution reaction. ACS Catal 5(9):5380-5387

81. Burke MS, Zou S, Enman LJ et al (2015) Revised oxygen evolution reaction activity trends for first-row transition-metal (oxy) hydroxides in alkaline media. J Phys Chem Lett 6(18):3737-3742

82. Stevens MB, Enman LJ, Korkus EH et al (2019) Ternary Ni-Co-Fe oxyhydroxide oxygen evolution catalysts: Intrinsic activity trends, electrical conductivity, and electronic band structure. Nano Res 12(9):2288-2295

83. Chung DY, Lopes PP, Martins PFBD et al (2020) Dynamic stability of active sites in hydr(oxy)oxides for the oxygen evolution reaction. Nat Energy 5(3):222-230

Publisher's Note Springer Nature remains neutral with regard to jurisdictional claims in published maps and institutional affiliations. 